\title{
Considerações acerca da utilização da Epidemiologia na avaliação dos sistemas de saúde
}

* Escola Nacional de Saúde Pública, Fundação Oswaldo Cruz $-R J$.

\section{Luis David Castiel*}

Este artigo discute as possiveis razões por que o instrumental epidemiológico não é utilizado no Brasil na avaliação de ações de saúde na amplitude em que seu potencial permite. Em primeiro lugar, apresenta formas pelas quais a avaliação em saude puiblica pode ser efetuada. $A$ seguir, mostra o papel da Epidemiologia na verificação dos resultados de programas de saúde. Por fim, são consideradas as dificuldades e fatores limitantes para a avaliação dos resultados de tais programas.

||||||||||||||||||||||||||||||||||||||||||||||||||||||||||||||||||||||||||||||||||||||||||||||||||||||||

\section{INTRODUÇÃO}

No processo de planejamento e administração de ações de saúde eficazes, é preciso prover os responsáveis pelos programas com dados relativos ao desempenho dos mesmos. A partir destas informações, seria possível efetuar os ajustes que se fizessem necessários ou, se fosse o caso, descontinuar o programa que se mostrasse insatisfatório. Entretanto, sabe. se que, de fato, tal racionalidade não costuma se fazer presente na realidade dos programas de saúde pública no Brasil.

Este trabalho procura identificar possíveis razões pelas quais o instrumental epidemiológico não é utilizado na am. plitude que seu potencial permite. Uma vez apontadas, seria possível o dimensionamento de medidas para lidar com tais limitações e, ao mesmo tempo, dispor de uma visão realista quanto ao alcance efetivo do uso da epidemiologia na avaliação dos programas de saúde pública.

\section{A Avaliação em Saúde Pública}

Num artigo escrito em 1974, Ramos distingue entre avaliação e controle. Para este autor, "o controle é conceituado como um processo ou mecanismo informativo e comprobatório dos planos e decisões formulados e tomados pela direção em seus diferentes niveis e também nos próprios cargos

Recebido para publicação em $07 / 05 / 86$. executivos, o que pressupõe a existência de um sistema adequado que forneça os dados necessários para julgar as reali- 
zações e para introduzir os fatores corretivos que as futuras execuções demandem" ". Ramos subdivide o controle em:

Direto

- consistindo em "verificar se as atividades estão sendo executadas de acordo com o estabelecido nas normas e regulamentos da organização;

Indireto - aquele que é realizado no que se refere às atividades e aos resultados. Para Ramos, o termo "avaliação" diz respeito ao controle indireto através dos resultados ${ }^{7}$. Dentro da técnica de programação local (CENDES/ OPS), a avaliação pode ser efetuada através de:

1) Produção - ou seja, a quantidade de trabalho realizado ( $\mathrm{n}$. de vacinações; $\mathrm{n}$ ? de consultas médicas etc);

2) Eficiência - que pode ser avaliada através de medidas como cobertura, custo, rendimento, concentração, grau de utilização;

3) Efeito - considerado em relação ao impacto proporcionado pela ação de saúde específica (ex. aspersão de inseticidas para o controle de mosquitos transmissores do dengue).

A partir desta abordagem, é possível visualizar que a participação da epidemiologia no processo de avaliação ocorre essencialmente no que diz respeito à verificação do "efeito" das ações de saúde.

No entanto, cabe enfocar um problema que se faz notar ao ler-se a literatura sobre avaliação: a confusão entre os termos e conceitos empregados. Não há homogeneidade na utilização do vocabulário nesta área. Um exemplo notório é a distinção entre "eficácia", "efetividade" e "eficiência" nem sempre muito bem definidas até mesmo por autores deste campo de estudo. Tal fato já denota a margem de dificuldades passíveis de serem encontradas ao se deparar como problema da avaliação dos serviços de saúde. Conforme Gremy, "a confusão do vocabulário reflete a diversidade dos pontos de vista de todos aqueles que se sentem ligados com a avaliação dos sistemas de sauide: epidemiologistas; administradores; economistas; pessoal que lida com assistência à saúde (médicos, enfermeiros, técnicos); o paciente individual; a população, tanto a população observada (a que efetivamente está vinculada com um programa ou servida por uma instituição) como a população teórica (a população-alvo de um programa ou de um hospital"') ${ }^{4}$.

Este mesmo autor destaca outra dificuldade: a complexidade de se avaliarem instituições de saúde, se comparadas a programas de saúde específicos. Diferentemente dos progra- 
mas, a instituição de saúde não possui objetivos claramente estabelecidos, pois trabalha baseada na teoria. Segundo Gremy, a avaliação de um sistema de saúde pode ser abordada em diferentes níveis:

- as estatísticas de saúde podem fornecer um quadro do estado de saúde da população. Com isto, seria possível indicar os setores onde as limitações do sistema de saúde se fazem mais presentes.

- estudos específicos podem cotejar a "importância relativa dos diferentes setores: atenção primária, atenção hospitalar, etc". ${ }^{4}$ (. . .)

Entretanto, a nosso ver na realidade brasileira, os programas de saúde não apresentam menor complexidade à avaliação do que as instituições de saúde. Aprofundaremos este ponto mais adiante.

\section{A epidemiologia na avaliação de sistemas de saúde}

Donabedian desenvolveu um esquema de avaliação que se baseia em 3 aspectos essenciais, a saber:

a) estrutura - refere-se a recursos físicos e materiais

b) processo - diz respeito ao desenvolvimento de atividades

c) resultado ("outcome") - relacionado aos efeitos da ação de saúde ${ }^{2}$.

Como é de conhecimento, a Epidemiologia dispõe de instrumental apropriado à determinação dos resultados ou, melhor dizendo, do impacto das medidas. Assim, é possível verificar se um programa de imunização está atingindo seus objetivos através do registro da diminuição da incidência da doença em questão. Todavia, as situações nem sempre se apresentam de forma a permitir este tipo de inferência.

Há ocasiões em que não é possível estabelecer com clareza um nexo de causa e efeito entre os supostos resultados de um programa de saúde e o status de saúde de uma população. Em primeiro lugar, a mensuração do nível de saúde está relacionada à sensibilidade dos instrumentos utilizados. Por exemplo, os indicadores tradicionais (mortalidade e morbidade) podem não servir para avaliar programas voltados para doenças crônico-degenerativas. $O$ sucesso de um programa deste tipo pode ser o aumento da prevalência da doença em questão, devido ao prolongamento da sobrevida do paciente.

Se pensarmos em indicadores mais elaborados, estes dependerão da definição do processo saúde-doença que se utiliza. São notórias as dificuldades conceituais que envolvem a consecução satisfatória desta tarefa. Goldberg et alii apontam para a complexidade crescente que implica a mensura- 
ção dos fenômenos vitais: o óbito - evento definido e mais facilmente detectável; a doença - já oferecendo maiores dificuldades diagnósticas e de registro; e, por fim, a quantificação da saúde - que implica ter-se claro o que se entende por "saúde" para se poder medi-la".

Em segundo lugar, as variáveis que interferem nas condições sanitárias da população são numerosas e escapam ao sistema de saúde. Habitação, alimentação, vestuário têm efeitos intensos sobre a saúde, e não se deve subestimá-los antes de considerar o status de saúde como resultante da eficácia de um programa de saúde. Pode-se erroneamente atribuir às medidas por programa os efeitos benéficos devidos a circunstâncias externas a ele.

Neste ponto, cabe indagar se os métodos de avaliação quantitativa da epidemiologia tradicional não se apresentam limitados para enfrentar tal problema. Carvalheiro diz que "avaliar o processo saúde-doença em sua dimensão coletiva não pode ser feito somente com a dimensão da epidemiologia tradicional (tempo, lugar e pessoa) se não se busca a essência do processo" 1 . Todavia, não se mostram tão facilmente operacionalizáveis as propostas ensejadas pela denominada "epidemiologia social".

Molinert et alii, do Vice-Ministério de Higiene e Epidemiologia de Cuba, afirmam que, para "se poder usar a epidemiologia na avaliação de saúde, requer-se terem sido resolvidas as seguintes premissas":

“- existência de um sistema nacional de saúde extenso e profundo;

- funcionamento de um grupo de programas de saúde;

- implementação de um sistema de vigilância, baseado na estrutura do sistema nacional de saude;

- bons registros e notificação estatística de casos $e$ outros dados necessários;

- vontade politica para encarar e solucionar de forma resoluta os problemas de saude" 6 .

Os autores não especificam quais destas condições são necessárias e/ou suficientes. Caso fossem aplicadas à situação brasileira, talvez não fosse possível satisfazê-las na sua totalidade . . Mas acreditamos que, mesmo sem preencher todas as premissas, há condições, na presente situação, para que a epidemiologia tome parte efetivamente na avaliação de programas de saúde. De qualquer forma, o método epidemiológico dispõe de potencial - que independe da vertente considerada - que deveria ser melhor explorado na programação de ações de saúde. 
A avaliação dos resultados envolve maiores dificuldades que a do processo. Algumas possiveis razões por que os planejadores não levam a cabo estudos dos resultados:

- freqüentemente os programas não apresentam seus objetivos estabelecidos de forma clara, que permitam aferir os resultados.

- Trata-se de uma atividade que envolve riscos. Os participantes do programa podem ser ver ameaçados, pois a avaliação talvez venha a demonstrar a inconveniên. cia da continuidade deste programa.

- A investigação dos resultados demanda uma abordagem metodológica mais rigorosa. Para isto, é preciso pessoal especializado e dispêndio consideravelmente maior de recursos, via de regra, escassos ${ }^{5}$.

Segundo Weiss, há situações em que possivelmente não vale a pena se efetuarem estudos avaliativos dos resultados:

1) "quando não há dúvidas acerca do" programa". Sua continuidade já está garantida através de outros critérios (pressão de grupos de interesse, acordos poli. ticos locais, eficácia já demonstrada);

2) "quando o programa não possui orientação definida. Seus participantes improvisam as atividades no dia-adia (. .) de forma que o programa varie e se modifique constantemente"

3) "quando não há recursos financeiros suficientes ou pessoal dividamente qualificado para conduzir a avaliação"8.

Podemos, então, considerar que, no panoroma dos programas de saúde no Brasil, as condições para se desenvolverem estudos avaliativos se apresentam, de forma geral, desfavoráveis. Isto não impede que se procure levar adiante projetos cuja possibilidade de êxito seja pequena. Mas, é preciso destacar que existem razões não-explícitas que influem nas intenções de avaliação dos resultados. Weiss sugere algumas situações:

- Adiamento de decisões: a sugestão de um estudo avaliativo pode servir para ganhar tempo para uma decisão;

- Transferência de responsabilidade - os administradores já sabem qual deve ser a decisão, mas não querên criar áreas de atrito. Então, solicitam uma "pesquisa cientifica" para legitimar suas posições;

- Relações públicas - o coordenador acredita que seu programa é bem sucedido e, assim, busca um modo de evidenciá-lo.

- Cumprimento de cláusulas das fontes financiadoras: Cadernos de Saúde Pública, R.J., 2(2):184-190, abr/jun, 1986 
- Muitos programas são financiados por agências externas que exigem avaliação de resultados para manterem o aporte de recursos ${ }^{8}$.

As circunstâncias assinaladas demonstram que os estudos avaliativos efetuados nestas condições podem se mostrar pouco porfícuos. Assim, é preciso ponderar se vale a pena participar de projetos que apresentem restrições e cons. trangimentos desta ordem.

\section{CONSIDERAÇÕES FINAIS}

As dificuldades que surgem para o desenvolvimento de estudos avaliativos não devem exercer um efeito paralisante. O conhecimento destas deve, isto sim, servir para orientar o epidemiologista a buscar formas realistas de participar na verificação da efetividade das ações de saúde. Uma das pers. pectivas reside nas recentes técnicas de avaliação epidemiológica rápida, na qual se procede à realização de estudos avaliativos onde há dados insuficientes, baixa qualidade dos registros e carência de recursos* ${ }^{*}$ É fundamental que as instituições do Sistema de Saúde considerem a avaliação como um elemento essencial no planejamento de ações de saúde e, mais importante, que proporcionem condiçōes para a sua efetiva realização. Somente assim poderemos ter programas de saúde que correspondam, de fato, às necessidades em saúde dos grupos para os quais tais programas são dirigidos.

*Szklo, M-Comunicação Pessoal.

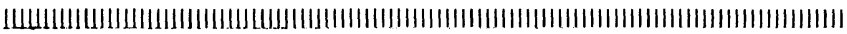

A discussion about possible reasons why epidemiologic methods are not widely used in evaluation of health actions in Brazil is developed. Firstly, ways by means Public Health evaluation can be performed are presented. Then, the role of Epidemiologg in outcome assessment of health programmes is shown. Finally, restraints and difficulties to perform outcome evaluation of such programmes are considered.

\section{REFERENCIAS BIBLIOGRÁFICAS}

1. CARVALHEIRO, J.R. Perspectivas de la investigación epidemiológica aplicada a la evaluación de la salud. In: SEMINÁRIO SOBRE USOS Y PERSPECTIVAS DE LA EPIDEMIOLOGIA. Buenos Ayres 7-10 nov. 1983. Washington, OPS, 1984. (Publ. PNSP, 84-47).

2. DONABEDIAN, A. The quality of medical care. Science, 200 : $856-64,1978$. 
3. GOLDBERG, M. et alii. Indicadores de saide e sanimetria. Aspectos conceituais de estudos recentes sobre a medição do estado de saúde de uma população. mimeo. [Trad. Rev. Epidemiol. Santé Publ., 27: 51-68, 1979, pt. 1 e 27: 133-52, 1979, pt. 2].

4. GREMY, F. Evaluation of medical action and of action in public health. Eff. Health Care; 1 (1): 11-23, 1983.

5. HOLLAND, W.W. ed. Evaluation in health care. Oxford, University Press, 1983.

6. MOLINERT, H.T. et alii. Epidemiologia en evaluación de la salud. Rev. Cub. Hig. Epidemiol., 22: 265-78, 1984.

7. RAMOS, R. O problema da avaliação em saúde pública. $R$. Saúde publ., 8: 305-14, 1974.

8. WEISS, C.H. Evaluation research. New Jersey, Prentice Hall, 1972. 